\title{
Experiences when employing different alternatives for envelope upgrading
}

\author{
P. Elguezabal* and R. Garay \\ Tecnalia, Sustainable Construction Division
}

\begin{abstract}
The challenges of achieving the 2020 goals in terms of energy savings and improving efficiency are guiding numerous research initiatives looking for more insulated envelopes, dealing with thermal performance of insulation materials and envelope systems. Nevertheless, the envelope integrates within the building and this improvement on the insulation performance has to be properly adopted, taking into account the interrelation of main elements composing the overall system (facade, frame, slabs, openings, partitions etc.), as well as side effects originated not only for new erected buildings, but specifically in renovation and retrofitting works. This paper describes real experiences when considering various options for upgrading the facade through the increase of the insulation capacity, starting from external overcladding prefabricated panels and ventilated facades, advancing to more sustainable low carbon systems and ending with even more highly insulated solutions employing aerogels. Lessons from these cases, where energy and hygrothermal assessments have being carried out, demonstrate the influence of the design and construction phases and the relevance of disregarded effects such as minor thermal bridges, uncontrolled craftsmanship on site, and moisture transfer for the different technologies considered. Finally, possible alternatives are provided to overcome some of the detected difficulties, such as combination with non-metallic structural components and building membranes, and being prepared for future challenges and new developments when these isolative elements are combined with other technologies, as for example, renewable energy harvesting devices.
\end{abstract}

Keywords: Thermal insulation, building envelope renovation, thermal bridges, performance under real conditions

\section{Introduction}

According to UNEP-SBCI (United Nations Environment Programme-Sustainable Buildings and Climate Initiative, 2015), collectively the building sector is responsible for about $40 \%$ of global energy consumption, including $12 \%$ of all fresh-water use and it produces up to $40 \%$ of our solid waste. Residential and commercial buildings consume $60 \%$ of the world's electricity, and the saving potential is quantified between 30 to $80 \%$ by the use of commercially available technologies.

In such context of high and unsustainable energy consumption, the 'Europe 2020' growth strategy became the main continental initiative describing the main path for improving this situation. There are three targets defined; reducing greenhouse gas emissions, increasing the share of renewables and improve the energy efficiency. Specifically for buildings, the EU Directives (Energy Performance of Buildings Directives, 2002), (EPDB Recast, 2010), and more specifically for each of the systems and products composing the building, the EU Construction Products Regulation (Construction Product Regulation [CPR], 2011) appoint the basic requirements for 'Energy economy and heat retention'.

\footnotetext{
${ }^{*}$ Corresponding author: P. Elguezabal, Tecnalia, Sustainable Construction Division. Tel.: +34 946430 850; Fax: +34946 460 900; E-mail: peru.elguezabal@tecnalia.com.
} 
Considering the dimension of the European building stock, 25 billion $\mathrm{m}^{2}$ of useful floor space in the EU27 (Economidou Atanasiu, Despret, Maio, Nolte, \& Rapf, 2011), with an average consumption of $280 \mathrm{kWh} / \mathrm{m}^{2}$ for the non-residential sector, is at least a $40 \%$ greater in the residential case. No significant variations of the stock are expected in various generations as in the case of the United Kingdom, where up to 75\% of the dwellings of the year 2050 already exist now (Ravetz, 2008).

Renovation of buildings has being adopted as one of the main actions to improve the inefficient situation towards the 2020 goals, with four main actuations:

- Improvement of the envelope's insulation capacity against external conditions.

- Improvement of efficiency of the equipment and services, mainly those related with heating, cooling and lighting.

- A higher harness of renewable energies by incorporating them into buildings.

- Improvement of the control and management of the energy demand.

Depending on the specific case and the initial conditions of the building to be renovated, the cost effectiveness of these actuations varies, but individually or collectively the four measures described are intended to significantly reduce the overall impact of buildings in terms of energy consumption.

\section{Energy improvement by increasing the insulation capacity}

The envelope as main heat exchanger element between the building and the external environment is easily responsible for more than $60 \%$ of energy losses in a conventional building considering the facade, roof and windows. Due to this strategic position this element has a high potential to improve the overall performance of the building by incorporating additional insulation.

Once the decision of renovating the building is taken, this measure supposes a basic concept with proven results aimed to reduce energy losses. It consists in providing a new layer, or extending the existing one within the section of the envelope, offering higher resistance to the heat flux in order to obtain a more internally insulated environment. Usually the first option to adopt, uniquely or combined with any other, is a concept that will in most cases give a return of the investment in a short-medium term.

For that purpose, various systems can be used in the external, internal or central section of the facade, such as external thermal insulation systems (ETICS), ventilated facades, insulation insufflation and internal insulation, but in the end the improvement is guided by the nature of the employed insulation.

Roughly insulation materials (Table 1 ) can be classified in three main groups:

- Conventional materials: Mostly developed by the chemical industry, the ones that are currently mostly used, due to the availability and well known performance. EPS, XPS, Polyurethane, Mineral and Glass Fibres are considered in this group.

- Organic insulations: Taking into consideration the current existing awareness of using more ecologically friendly solutions, several traditionally employed organic insulations have become popular and some others have been developed based on those ancient concepts. Among these, Wooden Fibers, Sheep Wool, Hemp, Cellulose or Natural cork are commonly used, using animal or plant source materials, to provide insulation. Their usual weakness is the difficulty to fulfil the fire resistance requirements. 
- Super-insulations: Based on advanced thermally performing materials, several developments have recently been carried out to provide more highly insulating materials, under the so-called super-insulation term aiming to obtain overall wall U-values below $0,2 \mathrm{~W} / \mathrm{m}^{2} \mathrm{~K}$. Two solutions are currently leading this concept: Aerogels made of low-density silica or carbon and Vacuum Insulation Panels where vacuum is encapsulated in a rigid external frame.

However, ideal conditions of insulation cannot be achieved as this material has to be integrated into a specific building part, the facade, interacting with all the building. This leads to new configurations, where traditional construction systems may substantially reduce the thermal performance of such materials when the relevance of thermal bridging in auxiliary elements is increased.

\section{Kubik as a demonstration platform for efficiency improvements on facade solutions}

KUBIK by Tecnalia is a an external building test facility oriented for R\&D activities aimed at the development of new concepts, products and services to improve the energy efficiency of buildings. The possibility of configuring different realistic scenarios to analyze the energy efficiency of isolated or coupled constructive elements covering the envelope, floors and partitions and their interrelation with building's HVAC and lightning systems, gives to Kubik a singularity to better understand the performance at room or at building level.

Additionally to the thermal performance, assembly and erection procedures are also evaluated and developed as well, especially for industrialized demountable solutions where joints and connections have to be designed to avoid local effects such as thermal bridges.

This flexibility for building realistic scenarios with different building configurations using various components and systems, gives to Kubik an internal and external variable look as the building changes with the specific testing case (Fig. 1).

During the technical development of a new or adapted process that starts simulating in virtual scenarios, continues with laboratory testing under standards and controlled conditions and finishes with the market deployment of the product, Kubik offers an intermediate step between the lab and real working conditions, allowing to evaluate the product's performance in a more realistic way prior

Table 1

Main characteristics of insulating materials for building applications

\begin{tabular}{lccc}
\hline & Thickness Range of panels $(\mathrm{mm})$ & Thermal Conductivity $\lambda\left(\mathrm{W} / \mathrm{m}^{\circ} \mathrm{K}\right)$ & Density range $\mathrm{kg} / \mathrm{m}^{3}$ \\
\hline EPS & $5-55$ & $0.046-0.030$ & $10-50$ \\
XPS & $30-180$ & $0.029-0.038$ & $20-50$ \\
Mineral Wool & $30-75$ & $0.032-0.04$ & $30-70$ \\
PU & $25-100$ & $0.023-0.029$ & $30-100$ \\
Sheep wool & $15-100$ & 0.04 & $13.5 / 15 / 20$ \\
Hemp Wool & $20-200$ & 0.04 & $40-60$ \\
Wood fibres & $20-200$ & $0.037-0.044$ & $45-200$ \\
Cellulose fibre & $40-100$ & 0.04 & $30-65$ \\
Natural Cork & $20-200$ & 0.04 & $120-205$ \\
Aerogel Panels & $20-60$ & 0.017 & - \\
VIPs & $10-60$ & 0.012 & 230 \\
\hline
\end{tabular}



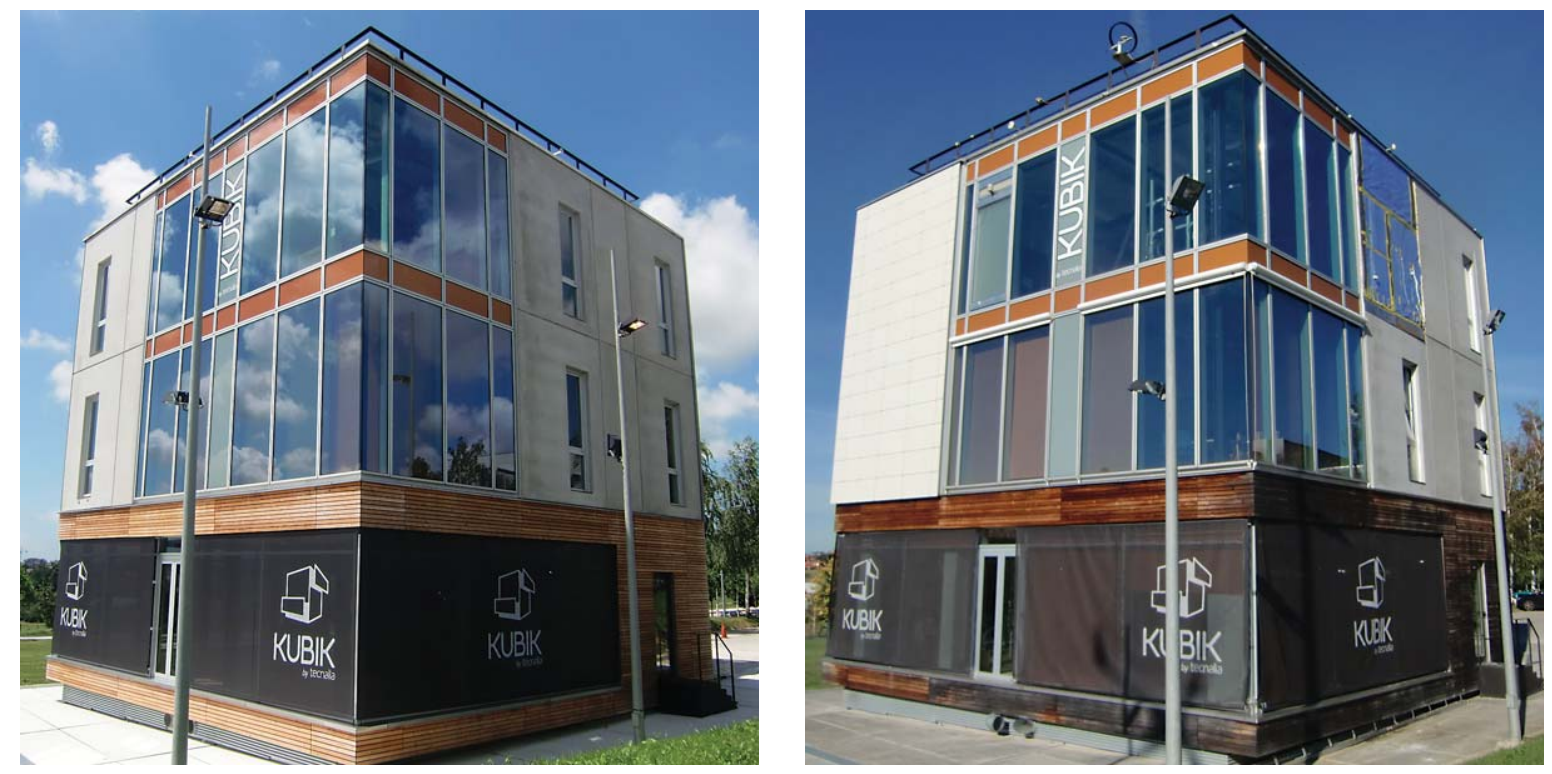

Fig. 1. Left: South view of Kubik in 2010; right: in 2014, with several facade changes in between.

to market deployment. This speeds up the product development and reduces risks of malfunction of highly innovative products or cases without previous experiences on such applications.

In the following chapters, three real cases are presented for different research projects that have being carried out in Kubik, as part of the development or demonstration of alternatives for energy improvement of currently existing buildings, as well as for the ones to be constructed in the future.

\section{Ventilated facade and ETIC as overcladding solutions}

\subsection{Description of the case}

The solution adopted was to attach directly the insulation to an existing facade in order to improve the overall U-value. The difference between both systems consists of the external layer and the generated air chamber in the case of the ventilated facade that does not exist in the ETIC solution.

The initial facade consists of a brick cavity facade whose heat transfer was experimentally obtained in the Kubik research facility. Two test-rooms in a vertical arrangement were conditioned in the west-oriented facade, including three beam elements to generate horizontal thermal bridges originated by slabs between storeys. This typology is present on Spanish buildings erected between 1960 and 1990 and was designed using equivalent materials and thicknesses to those solutions.

The experimentation carried out in the ERAIKAL project (Basque Government, 2012) assessed the thermal bridge quantification in real conditions determining the influence of the slab thermal bridges in a $20 \%$ by linear meter. The variation of the U-value from an initial situation of $1.89 \mathrm{~W} / \mathrm{m}^{2} \mathrm{~K}$ was improved up to $0.6 \mathrm{~W} / \mathrm{m}^{2} \mathrm{~K}$, with a renovation system consisting of $50 \mathrm{~mm}$ of insulation and $50 \mathrm{~mm}$ of air chamber (Fig. 2). 


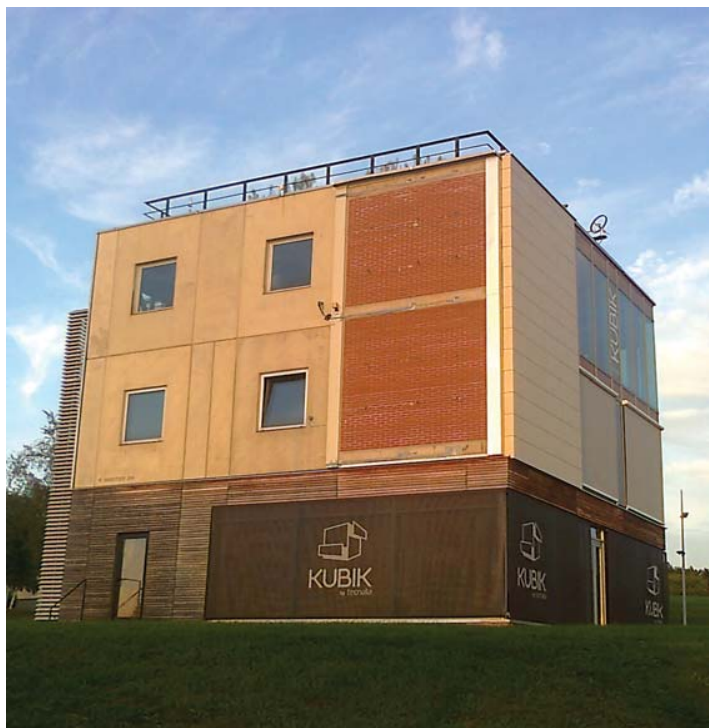

Phase 1: Brick Cavity Façade

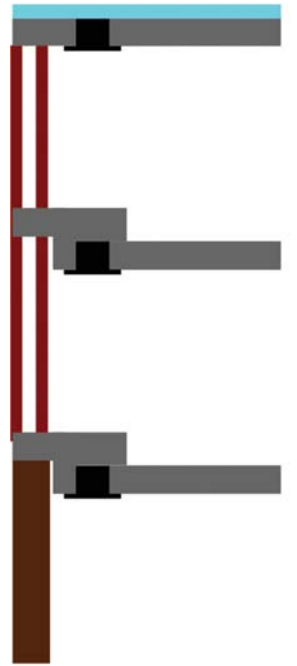

Phase 2: Ventilated Façade

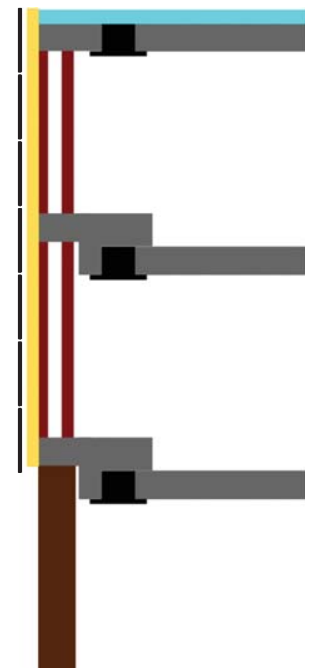

Fig. 2. Left: Brick facade test configuration in Kubik (2012); right: configuration of each experimental phase.
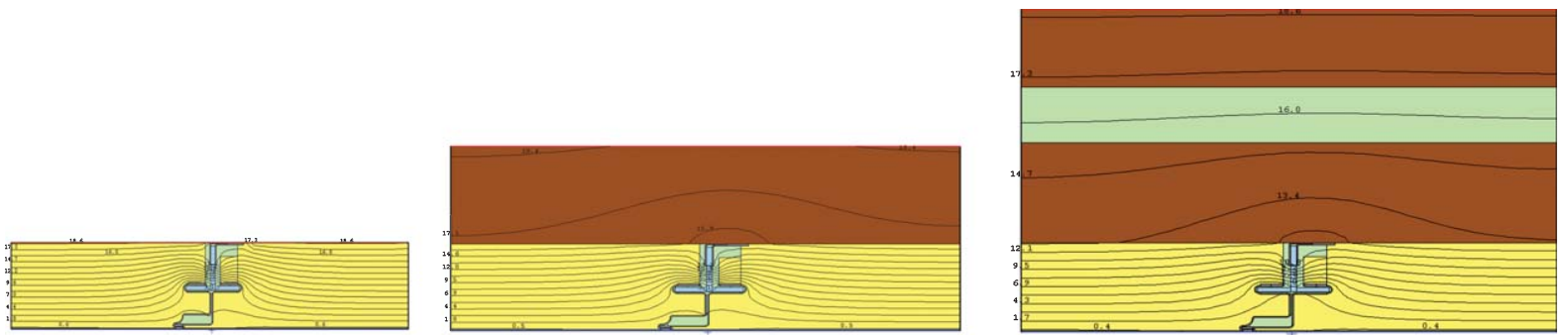

Fig. 3. ETIC solution's thermal assessment for different cases of existing facade.

As an alternative, an overcladding solution was calculated for the same facade but also for some other situations as well (Fig. 3). In this case the system was composed by $80 \mathrm{~mm}$ of insulation, but with the particularity of being an industrialized ETIC system. This design combining insulation and low conductivity plastic profiles was developed in the SIREIN+ project.

In this case simulations demonstrated the relevance of the initial situation and the influence of joining systems to obtain thermal break-free solutions. From the initial situation the transmittance was lowered to $0.48 \mathrm{~W} / \mathrm{m}^{2} \mathrm{~K}$ and the linear thermal bridge coefficient $\psi$ was demonstrated to be negligible for initial U-values below $1.5 \mathrm{~W} / \mathrm{m}^{2} \mathrm{~K}$.

\subsection{Relevance of the continuity of the insulation}

The main issue in systems for retrofitting as the ones presented is the combination between various materials and solutions for solving the thermal performance. The relevance of the geometries in two and three dimensions, different densities, conductivities and other effects have a significant influence in terms of the final solution behaviour, as they may interrupt the continuity of the insulation layer. 


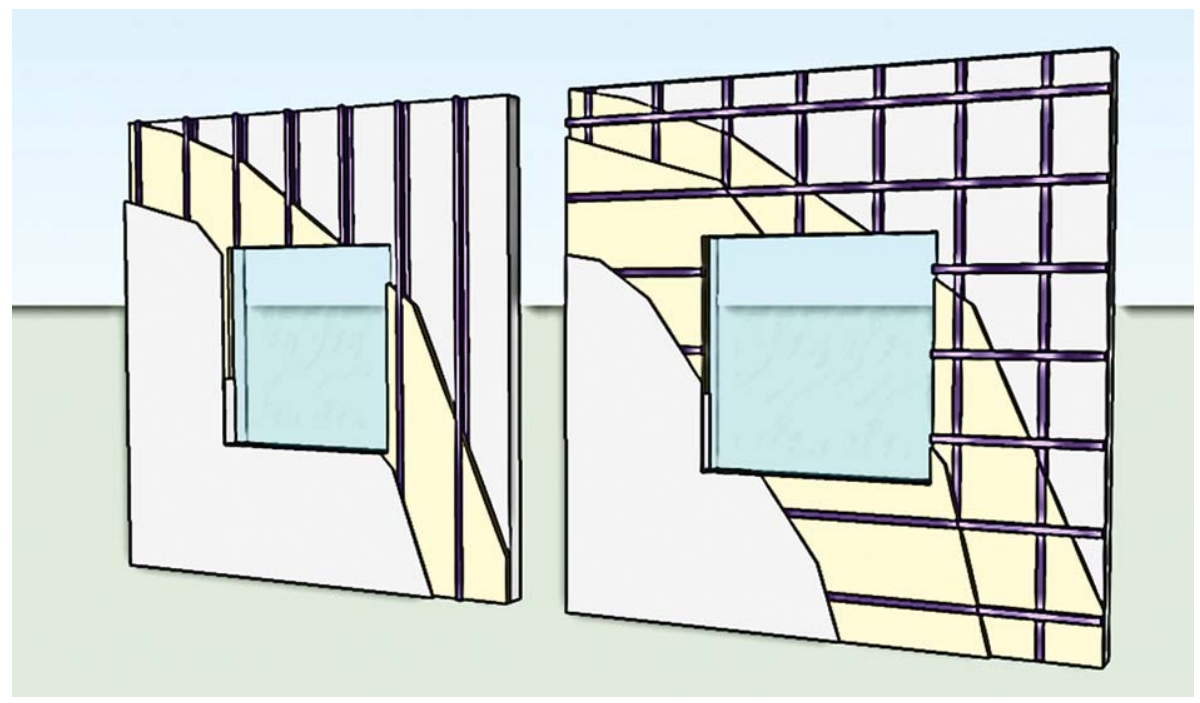

Fig. 4. Profile arrangements in an internal insulation system. Left: vertical; right: crossed.

The dynamic effects due to the presence or absence of massive solutions represent a phenomenon that can also have a significant effect in the final behaviour (Martin, Flores, Escudero, Apaolaza \& Sala, 2011).

Additionally, the use of industrialized solutions highlights the importance of the joints for fulfilling other requirements such as water and air tightness that have to be properly designed to comply with the expected performance (Capozzoli, Gorrino \& Corrado, 2013) as well as to avoid the origin of new pathologies such as condensations.

\section{Highly insulating material in an internal insulation system}

\subsection{Description of the case}

High performing materials due to their excellent relation between thickness and conductivity provide a very promising development path for internal insulation systems, as they solve in less space the indoor actuation when available surface is usually a valuable asset.

In this case, the relevance of the support profile system was studied in the AEROCOINS project, in order to solve the internal insulation system without losing the benefits provided by the aerogel material. Cold formed steel profiles and wood studs as common solutions were studied, and as alternative, composite profiles, which are recently becoming a new constructive element as thermal effective solutions with mechanical properties (FACOMP, 2013). The position of the profile was also assessed considering vertical and crossed orientations Fig. 4.

\subsection{The structural frame to support the system can ruin the super insulation effect}

The study about the influence of the profiling options has demonstrated that depending on the configuration chosen, the increase of the thermal conductivity changes (Garay, 2013). For the case 

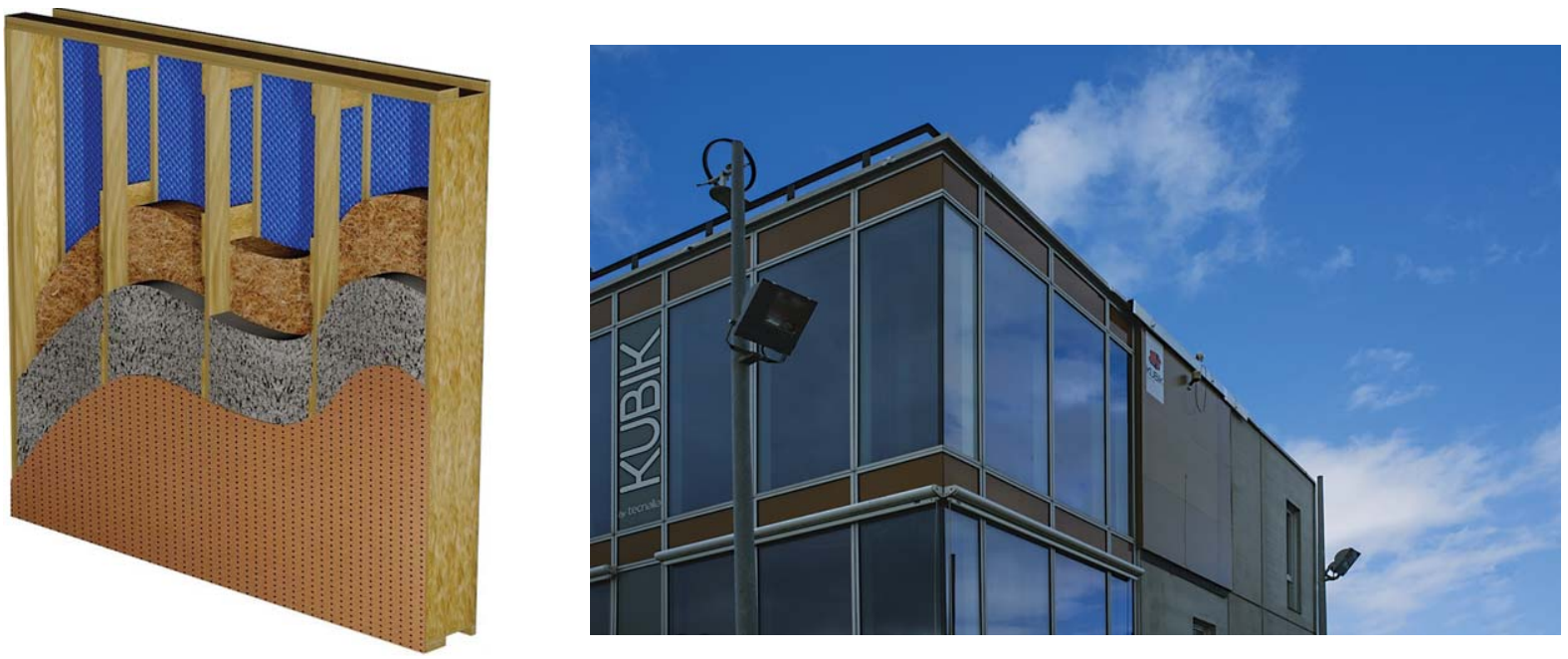

Fig. 5. Left: Scheme of the main elements composing the system; right: installed panel in Kubik.

of vertical steel profiles, this increase varies between $40 \%$ to $70 \%$, for wooden studs conductivity is higher by at least $40 \%$ as well. Some crossed configurations for metal or wooden stud systems increase the overall thermal conductivity in $15 \%$, but require more space for the framing, not aligned with the thin wall concept of such solution. The best solution is the one employing plastic composite profiles, as the decrease of the thermal resistance of the wall results significantly lower $(<10 \%)$.

\section{Wooden panels insulated with hemp-lime}

\subsection{Description of the case}

As a final contribution, a hemp-lime biocomposite, framed in a structural factory-made panel is presented, combined with hemp fibre as main insulator. The benefits of the solution, offering thermal inertia and regulating internal humidity, combined with the breathable insulation, gives to this solution a competitive performance for a low embedded energy solution.

The $0.04 \mathrm{~W} / \mathrm{mK}$ conductivity of the fibres combined with $0.074 \mathrm{~W} / \mathrm{mk}$ of the biocomposite provides a very competitive solution with final U-values close to $0.15 \mathrm{~W} / \mathrm{m}^{2} \mathrm{~K}$ in a $300 \mathrm{~mm}$ section.

This system was installed in Kubik at the end of 2014 as part of the HEMPSEC project and is still being monitored (Fig. 5). Although final results are still not available, similar experiences have demonstrated the overall effectiveness in terms of energy efficiency as well as overall performance for an eco-friendly facade like this, with special fire resistance performance (up to $60 \mathrm{~min}$ ) for such a solution.

\subsection{Eco-efficient solutions do perform similar to conventional systems}

For this case the use of materials from the same natural origin integrated into an eco-friendly balanced solution, is likely to perform similar to conventional systems (Latif, Ciupala \& Wijeyesekera, 2014), in a panel with more thickness, but offering an interesting alternative for energy efficient envelopes as well as for overcoming the difficulties of fire resistance performance. The performance of 
the facades and its interrelation with the humidity are being currently assessed as well, highlighting the necessity of providing additional information to the steady state calculated U-values (Shea, Lawrence \& Walker, 2012) to get a more detailed performance of the solution.

\section{Conclusions}

The increase of insulation is a simple actuation for energy renovation of buildings with a lower cost than most of the possible alternatives for energy improvement of buildings, with a good return of the investment, thanks to the feasibility of the results.

Different alternatives have been presented in the paper to renovate facades under this scope. Firstly overcladding solutions are described highlighting the relevance of thermal bridge treatment in order to obtain a balanced solution, decreasing initial U-values from $1.89 \mathrm{~W} / \mathrm{m}^{2} \mathrm{~K}$ to a range between $0.48-0.6 \mathrm{~W} / \mathrm{m}^{2} \mathrm{~K}$. Secondly, the influence of the framing distribution to support an aerogel blanket has been studied, resulting that less conductive composite profiles are those that less affects the final insulation performance, with a decrease below the $10 \%$. Finally hemp-lime-based insulated panels are presented as competitive and sustainable solutions with additional features, thanks to the higrothermal performance of such solutions.

Although there is not a standard solution that better performs in all cases, it is important to understand how these solutions are integrated in order to get as much efficiency as possible. Research in the development of new materials with new or improved performances is needed, but it is necessary as well to solve how these are integrated in the building's system, considering the adjacent elements as well as different stages in the building's life cycle. A non-coordinated operation can waste all the effort and the investment and what is even worse, create new problems that did not exist initially.

Finally a better understanding of all these concepts is required, in order to be prepared for future developments when combining isolative solutions with renewable energy harvesting devices, as well as with efficient control and management systems, in line with more complete and energy efficient upgrade measures.

\section{Acknowledgments}

The research leading to the results reported in this work has received funding from the European Union Seventh Framework Programme FP7/2007-2013, the Eco-Innovation Initiative of the European Union, the Spanish Government and the Government of the Basque Country, under the following projects: Hybrid Nanomaterials for Cost-Effective Building Super-Insulation Systems (AEROCOINS, Grant Agreement no260141), Pre-fabricated, pre-dried panelized system of hemp-lime construction (HEMPSEC, ECO/12/332972), Sistema Integral de Rehabilitación Energética (SIREIN+), Estudio de investigación sobre eficiencia energética y viabilidad de la aplicación de fachadas ventiladas en soluciones de rehabilitación (ERAIKAL-12).

\section{References}

Basque Government (2012). ERAIKAL - 12 Project Research Study in energy efficiency and feasibility of ventilated façades as renovation solution. Retrieved April 17, 2015 from http://www.garraioak.ejgv.euskadi.eus/contenidos/informacion/estudiokubik/ eu_kubik/adjuntos/kubik3.pdf 
Economidou, M., Atanasiu, B., Despret, C., Maio, J., Nolte, I., \& Rapf, O. (2011). Europe's buildings under the microscope. A country-by-country review of the energy performance of buildings. Buildings Performance Institute Europe (BPIE).

Capozzoli, A., Gorrino, A., \& Corrado, V. (2013). A building thermal bridges sensitivity analysis. Applied Energy, 107, $229-243$.

Council Directive 2002/91/EC on the Energy Performance of Buildings. EPDB.

Council Directive 2010/31/EU, on the Energy Performance of Buildings. EPDB (recast).

Council Regulation (E.U.) No. 305/2011 laying down harmonised conditions for the marketing of construction products. CPR

FACOMP, Polymeric nanocomposite profiles for curtain walls, EU FP7 grant agreement no. 221989. Retrieved April 17, 2015 from http://cordis.europa.eu/project/rcn/94166_en.html

Garay, R. (2013) New challenges on façade insulation systems with superinsulation materials. First Workshop. High Performance Thermal Insulation (HPI) - 2013 Towards Near Zero Energy Buildings. 27th \& 28th November. Würzburg, Germany. Retrieved April 17, 2015 from http://www.buildup.eu/sites/default/files/content/Workshop_First_Announcement.pdf

Latif, E., Ciupala, M. A., \& Wijeyesekera, D. C. (2014). The comparative in situ hygrothermal performance of Hemp and Stone Wool insulations in vapour open timber frame wall panels. Construction and Building Materials, 73, 205-213.

Martin, K., Flores, I., Escudero, C., Apaolaza, A., \& Sala, J. M. (2011). Problems in the calculation of thermal bridges in dynamic conditions, Energy and Buildings, 43, 529-535.

Ravetz, J. (2008), State of the stock - What do we know about existing buildings and their future prospects? Energy Policy, 36(12), $4462-4470$.

Shea, A., Lawrence, M. \& Walker, P. (2012). Hygrothermal performance of an experimental hemp-lime building. Construction and Building Materials, 36, 270-275.

United Nations Environment Programme - Sustainable Buildings and Climate Initiative, Retrieved March 30, 2015 from http://www.unep. org/sbci/AboutSBCl/Background.asp 